\title{
Clinical Stage I Cutaneous Melanoma AJCC v8
}

National Cancer Institute

\section{Source}

National Cancer Institute. Clinical Stage I Cutaneous Melanoma A/CC v8. NCI Thesaurus.

Code 137648.

Stage I includes: IA: (T 1a, N0, M0); IB: (T1b, N0, M0); (T2a, N0, M0). T1a: Tumor measuring less than $0.8 \mathrm{~mm}$ in thickness. Ulceration status: Without ulceration. T1 b: Tumor measuring less than $0.8 \mathrm{~mm}$ in thickness with ulceration, or $0.8-1.0 \mathrm{~mm}$ with or without ulceration. T2a: T umor measuring more than 1.0 and equal to or less than 2.0 $\mathrm{mm}$ in thickness. Ulceration status: Without ulceration. N0: No regional lymph node metastasis detected. Presence of in-transit, satellite, and/or microsatellite metastases: No. M0: No evidence of distant metastasis. LDH level is not applicable. (AJCC 8th ed.) 